International Journal of Linguistics, Literature and Translation

ISSN: 2617-0299 (Online); ISSN: 2708-0099 (Print)

DOI: 10.32996/ijltt

Journal Homepage: www.al-kindipublisher.com/index.php/ijltt

\title{
Learner Autonomy: Learners' Perceptions on Strategies to Achieve Autonomy in an EFL Classroom
}

\author{
Muhammad Amir Saeed 8(D) \\ Lecturer of English, Department of English Language and Literature, CAAS, Dhofar University, Salalah, Oman \\ $\triangle$ Corresponding Author: Muhammad Amir Saeed, E-mail: aamirsaeedshaikh@gmail.com
}

ARTICLE INFORMATION

Received: February 02, 2021

Accepted: March 04, 2021

Volume: 4

Issue: 3

DOI: $10.32996 / i j l l t .2021 .4 .3 .17$

\section{KEYWORDS}

Learner autonomy, autonomy support model, Arab EFL

classroom, motivation, peers role, social media, learner's perception, self-regulated learning, teachersupport in autonomy

\section{ABSTRACT}

Learner autonomy is considered as one of the most important factors contributing to lifelong learning for language learners studying at university. This is primarily because learners were likely to feel motivated and engaged when they were given the freedom to take charge of their learning. Higher Education in Oman has been relatively a recent phenomenon that was introduced three decades before. Ministry of Higher Education in Oman emphasis developing lifelong learning and self-study skills in learners studying at a higher educational institution in Oman. Most of the learners studying at higher educational institutions were taught by the native Arab speakers in schools, and they were mostly dependent on their teachers for the completion of different academic tasks in schools. Learner autonomy is now not desired but the obligatory aspect of learning under the current unprecedented circumstances where learners were required to take control of their learning, complete their tasks, assignments and projects on their own and where teacher intervention is minimal due to 'remote teaching' situation. The prevalent situation where technology has now taken the pivotal role in shaping the 21st century teaching and learning process, it is high need for the EFL learners studying at tertiary level at the university should be autonomous and critical thinkers who can control of their learning process and aware of the necessities of learning. Therefore, considering the learners' spoon-feeding learning attitude at school and fast-changing learning requirement, the researcher aimed at identifying learners' understanding and perceptions to achieve autonomy in learning in an EFL Context. This study also aims at finding out learners' belief on the role of peers, teachers and social media in achieving autonomy in learning. By using mixed method approach, the researcher designed a 35-items Likert scale questionnaire and semi-structured interview questions to record the perceptions of $135 \mathrm{EFL}$ learners studying at tertiary level in a private university in Oman. The results of the current study revealed that students were aware of the concept of learner autonomy and they believe that teacher's scaffolding, peer intervention and use of social media platforms can not only help them to foster autonomy in them but also to gain confidence, motivation, self-esteem, sense of responsibility and selfdetermination in an EFL language learning environment. The implications of this research will assist the EFL teachers and the administration to consider EFL learners learning needs and learners' self-efficacy and attitude towards their own learning.

\section{Introduction}

Learner Autonomy (LA) has recently not been considered as the desired characteristic in learners but a necessity, especially the unprecedented circumstances like the Covid-19 pandemic. Learner autonomy has received considerable attention from researchers both from ESL and EFL context for the last four decades. LA focuses on learner agency in which a learner has a proactive attitude towards his learning and he is the master of his learning process.

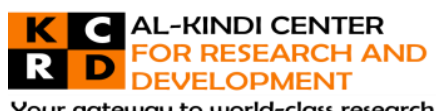

Your gateway to world-class research

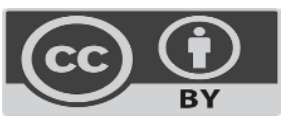

Published by Al-Kindi Center for Research and Development. Copyright (c) the author(s). This open access article is distributed under a Creative Commons Attribution (CC-BY) 4.0 license 
LA has been defined extensively, and various definitions have been presented by different researchers in the past. Autonomy is defined as "the ability to act and make decisions without being controlled by anyone else" (Oxford Advanced Learners' Dictionary online, n.d.) and it is "the quality or state of being self-governing; self-directing freedom and especially moral freedom." (Merriam Webster online dictionary). Learner autonomy has been defined as a multifaceted concept that enables a learner to take control of his own learning (Holec, 1981; Fredholm et al., 2015), monitoring and reflecting his exercises of various strategies both inside and outside of a formal learning context (Benson, 2011) considering his socio-cultural, psychological and critical conceptions. (Benson, 2013, Benson, 1997; Oxford, 2003). Learner autonomy is manifested in learner by developing curiosity in learning, enhancing self-confidence and motivation by engaging the learner in meaningful activities, and increasing his self-esteem (Meyer et al., 2008) and regulating and controlling his own learning process. (Zimmerman, 2000).

Learner autonomy cannot be attained in isolation; rather, it depends on collaborative efforts and leaner's dependence on several factors (Little,2000) and the learning environment which allows a learner to determine his preferences and pace for learning (Benson, 2017; Teng \& He, 2015). The recent technological development has provided a variety of learning options like flipped classrooms, online education, Learning Management Systems have provided the opportunity to learn beyond the boundaries of traditional classrooms (Baby \& Saeed, 2020; Benson 2017) which have facilitated learners a conducive environment to develop autonomy.

In an Arab teaching and learning context in schools, teachers were responsible for instigating knowledge and, in some situations, spoon-feeding the learners and they were learning passively. The learners in schools were least bothered or considered least responsible for their success or failure. However, at university, a learner is considered to be responsible for his learning and ultimately for his success or failure. EFL learners who enrol in undergraduate programs were considered to be aware of autonomy and were expected to take complete responsibility for their learning (Field et al., 2014).

Furthermore, at a university level, a study of only the course material is not sufficient for a learner and the learner has to explore further knowledge by himself. A passive learner will never be able to bring himself to this level. Therefore, the learners must take charge or responsibility for their learning so that they can adjust themselves in an academic setting of higher education. Even in some cases if a student has learned everything related to his course material but they need intensive practice through self-study either at the institution or at home.

In the Asian and Middle Eastern context, the learners were interdependent due to the societal norms of collectivism to achieve autonomy (Blidi, 2017; Benson et al., 2003). Though, these students were facilitated with high-tech technological resources to facilitate both face-to-face and online learning under the current circumstances yet wisely selected strategies were required to foster autonomy in learners (Ghazali,2020). Lastly, one of the graduate attributes of learners at Dhofar University is lifelong learning and self-dependence to make future decisions that the learners need after they graduate from university. This goal cannot be achieved unless every individual learner at the university is capable of taking responsibilities and decisions on his own.

\subsection{Factors affecting learner autonomy}

Several factors affect learning autonomy and they are directly or indirectly connected to each other i.e. locus of control, motivation (both intrinsic \& extrinsic), choice, the capability to recognize learning needs and to assess learning outcomes, the capability to pursue and utilize knowledge, (Lee, Mann, \& Frank, 2010; White \& Fantone, 2010; White, 2007; Levett-Jones, 2005; Regan, 2003).

Several effective factors have been introduced in the literature, and successful language learners seem to possess similar traits. Some of the most frequently examined factors include Brown's (1994) personality factors (i.e. self-esteem, risk-taking, inhibition, anxiety, empathy, and extroversion), learning styles (Oslund, 2015; Rinkoff, 2007) and learning strategies (Griffith \& Sourc, 2020; Oxford \& Amerstorfer, 2018, Oxford, 2002).

Scharle and Szabó (2007) think that "personality traits, preferred learning styles, and cultural attitudes set limits to the development of autonomy." David Little did exclusive research on learner autonomy. According to Little (2001), to develop learner autonomy, the learner should concentrate on two very significant factors: collaboration and reflection. According to him, collaboration through social interaction with classmates and other people outside the classroom. Collaboration in developmental psychology and education is generally linked with the cognitive, social, and affective features of learning. The other important factor is Reflection which is internal reconsiderations and reflections on the process of language learning both inside and outside the classroom, activities, like writing and keeping a diary of reflections were important factors contributing to developing learner autonomy. 
Deci and Ryan (2016) while referring to the Self-Determination Theory, argued that competence and relatedness were the two most important factors contributing to learner autonomy. They argued that humans tend to feel more relaxed and connected to society when they involve themselves in different activities socially and these processes linked them towards more selfregulation and autonomy.

Oxford (2015) in her study reveals various types of autonomous learners. According to her 'Psychological self-Autonomous learners' were proficient in controlling their emotions, beliefs and their learning styles. Next were the 'Emotionally Intelligent learners' who have control over their intrinsic motivation, understanding and managing other people and classmates' emotions and adapted their emotions according to the situation. Then the "Resilient learner" fights back in all of the difficult situations either by themselves or they use their social factors to handle the situation, however, they were always successful due to their resilience in learning. "A psychologically engaged learner" always gets engaged with effective study materials and meaningful tasks through his conscious efforts and continuous engagement in learning. "A Self-determined Learner" uses his intrinsic motivation to achieve autonomy and competence. Benson (2011) has arguably divided learner autonomy into three different categories i.e. psychological, political and technical learner autonomy. According to him, 'Psychological autonomy' can be called a 'capacity to develop an ability and an attitude that will assist a build-up responsibility for his learning. 'Political autonomy' is the autonomy that will enable a learner to control the steps and contents of learning. For example, how to control individual and group learning in an educational context. Lastly, he elaborates on 'Technical autonomy' which happens outside the educational institution and without any involvement of the teacher in learning.

In the context of Oman, Borg and Al-Busaidi (2012) from Sultan Qaboos University, reported that a negligible number of learners studying at the university level was somewhat aware of the concept of learner autonomy, whereas, a vast majority of students were completely unaware of the concept of learner autonomy. Specifically, the tertiary level students at university find themselves confused and helpless and do not have an idea of how to take control of their learning at the university. This situation is not only evident in Omani students studying in higher education institutions but also in some developed countries like Australia, a large number of EFL learners were unaware of the concept of learner autonomy. (Field et al.,2014).

In the context of Dhofar University in the Sultanate of Oman, the majority of the students exiting from high school education tend to depend mostly on teachers for their learning. As these students register at the tertiary level in university, the attributes and learning habits developed in learners at school hinder their learning autonomy (Basri, 2020). However, the recent developments in learning and education demand learners to equip themselves with this lifelong learning phenomenon of autonomy. Additionally, the researcher observes that most of the previous research on Learner Autonomy has been done either in the European or the Western Context and very limited research work is done in the context of Arab EFL learners specifically in Oman's context. Having discussed the importance of learner autonomy and considering the current scenario, the current study aims to find out the answers to the following questions:

1.What are the perceptions of learners studying at Dhofar University on learner autonomy?

2.What practices do they think were helpful for them in achieving autonomy at the university?

Since the situation was critical with most tertiary level students studying in the university. Therefore, the researcher decided to select only tertiary level students as a population in this study.

\section{Research Methodology 2.1 Research Design}

The data is collected in the form of a questionnaire and semi-structured interviews. The questionnaire written to measure the reflections on learner autonomy and some of the question items has been adapted from Camilleri \& Malewska-Peyre (1997) questionnaire to record the perceptions of tertiary learners on autonomy at the university. The researcher designed a 35-items Likert questionnaire for students. The questionnaire was piloted and got approved by the University Research Board (URB) to maintain the research integrity. The questionnaire was then translated into the Arabic language for clarity and intelligibility so that the collected data presents the true picture of learners' reflections. The questionnaire assesses four sub-dimensions (mention the dimensions). The reliability of the questionnaire was checked by using Cronbach's Alpha and it was more than 0.7 .

\subsection{Participants and data collection}

The questionnaire was administered on a random sampling basis to $135 \mathrm{EFL}$ learners age between 18-21 years with an average age of 19.4 studying at the Foundation Year Program and $1^{\text {st }}$ Year EFL students at the Department of English Language and Literature. The data and perceptions of EFL were collected through questionnaires and interviews. The data has been collected through questionnaires and semi-structured interviews. The collected data has been recorded by using Microsoft Excel and Endnote.

Page | 152 


\subsection{Ethical Considerations}

The participants in this research participated voluntarily. All the participants in this research were assured of complete confidentiality and anonymity of this information. The questionnaire and interviews were conducted after getting approval from the University Research Board (URB). Ethical consent has been taken from the participants to share the data publicly.

\section{Results}

The questionnaire items have been grouped to analyse the relevant question items keeping the same question number as it was given in the questionnaire to elaborate the data properly. The information has been shown in graphs to compare and contrast and analyse the collected information and to deduce results. For each group of questions, a graph has been used to demonstrate the result and the analysis of the responses given is discussed below each of the graphs.

\subsection{Perceptions of EFL learners in Dhofar University on learner autonomy}

Statement 1. I know and understand the importance of learner autonomy.

Statement 2. To be an independent learner, I need basic language skills

Statement 3. An EFL learner needs to have the confidence to learn independently.

Statement 4. It is very important for every EFL learner to become an independent learner.

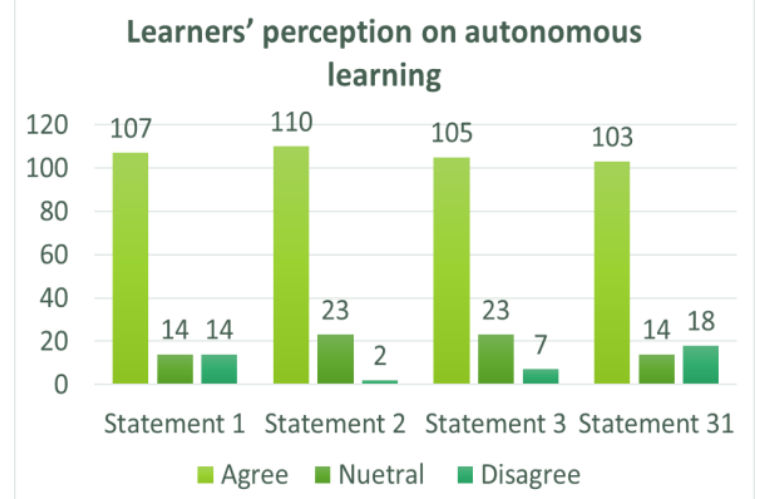

Fig. 1. Learner's perception on learning independently

Analysis: The researcher has found that the majority of learners agree that they were aware of the concept and importance of being independent in learning and they acknowledge the fact that almost all of them need to be confident and well aware of basic language skills to become independent language learners which is an essential element of learning at tertiary level at the university. Only one-fifth of EFL learners showed were either neutral or disagree with the idea.

\subsection{Perceptions of EFL learners in Dhofar University on Teacher's scaffolding}

Statement 6. I seek my teacher's help in completing the tasks.

Statement 7. I depend more on my teacher in understanding the lesson.

Statement 26. A teacher's presence is necessary for the class in doing all the tasks.

Statement 30. My teacher uses different methods to develop independent learning in us.

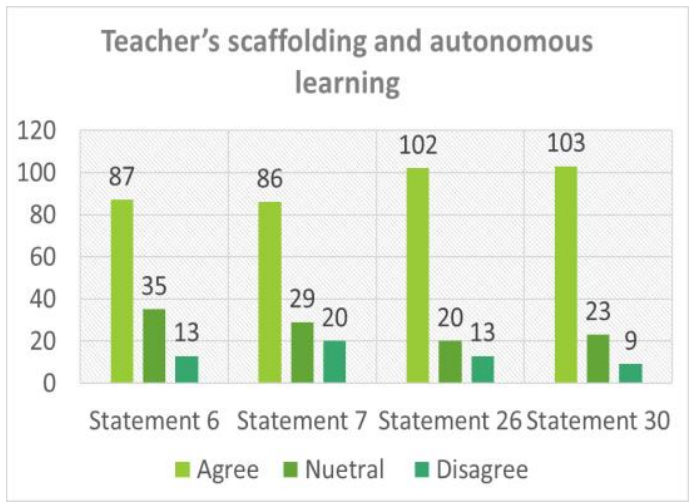

Fig. 2. Learner's perception on teacher's scaffolding 
Analysis: A large number of EFL learners at the tertiary level in Dhofar University show their agreement and emphasis on the presence of their language teacher to assist them in the successful completion of different tasks and they also acknowledge their teachers were using different methodologies to build up independent learning in them. One-third of the language learners inform that they want to understand and complete the assigned tasks or assignments by themselves. However, a vast majority affirms that the role of a teacher is vital as he guides learners using different techniques for successful completion of tasks and achievement of autonomy in learning.

\subsection{Perceptions of EFL learners on Peer's role in attaining autonomous learning}

Statement 16. I feel encouraged when my peer explains a task in the class.

Statement 17. Peer's feedback motivates me to learn more.

Statement 18. I feel inferior when I ask a peer on a specific topic.

Statement 19. The teacher should encourage peer teaching in the class.

Statement 20. Peer teaching helps attain autonomous learning

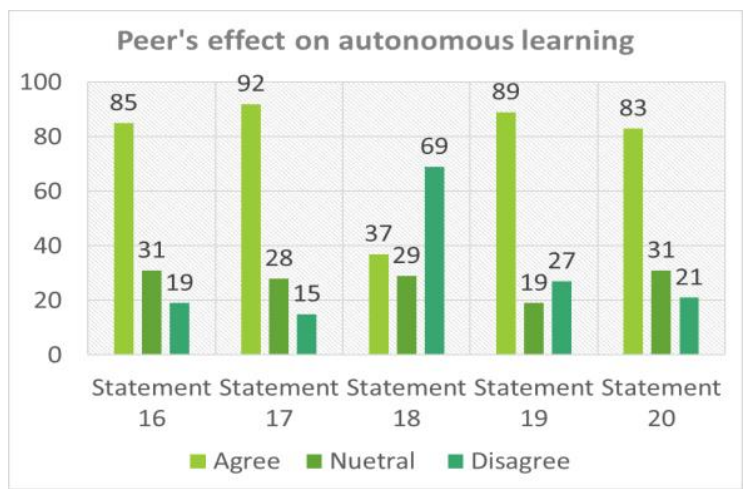

Fig. 3. Learner's perception on peer's role in fostering

Analysis: The researcher finds that peer teaching has a positive effect on EFL learners' motivation, learning process and the achievement of independence in their learning. Overall, the learners feel encouraged when they were explained a task by their classmates in the class. Peer teaching also motivates EFL learners to learn with interest. However, a large number of students disagree that they never feel inferior or disrespected when they ask their peer on any topic in the class. Two third of EFL learners believe that the teacher should encourage peer teaching in the classroom because they think peer teaching helps attain learner autonomy in an EFL classroom.

\subsection{Perceptions of EFL learners on the role of assignments and projects in fostering Learner Autonomy}

Statement 11. I like doing projects and assignments independently to build my confidence.

Statement 12. Assignments and projects help me to improve my knowledge.

Statement 13. I feel more autonomous after doing assignments and projects inside and outside the class.

Statement 14. I always try to do more than I am requested to do in assignments and projects.

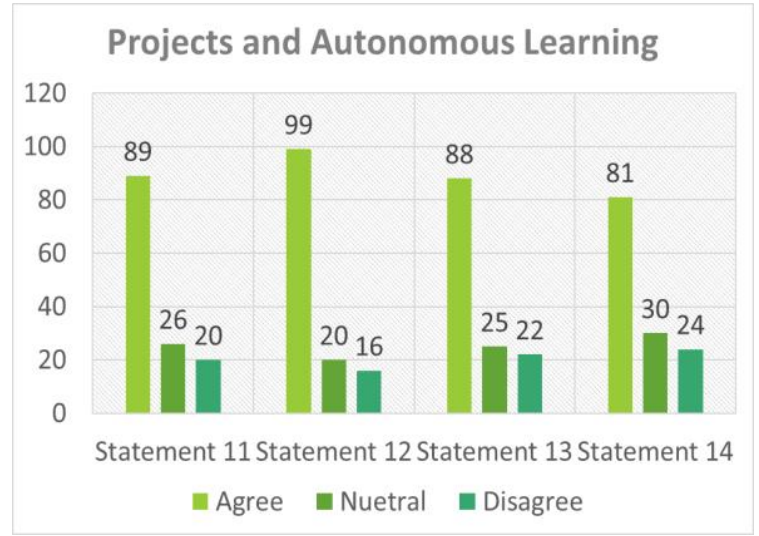

Fig. 4. Learner's perception on the role of projects and assignments 
Analysis: The research assessed the role of assignments and projects to inculcate autonomy in learners. More than $70 \%$ of respondents believe that doing different kind of projects and assignments independently help them to build their confidence. The learners also observe that assignments and projects also help them develop their knowledge and understanding of the course, ultimately leading them to feel more autonomous after doing assignments and projects inside and outside the class. A majority of learners also admit that they always try to do more than they were requested to do in assignments and projects as they feel confident and independent by solving them.

\subsection{Perceptions of EFL learners on the role of social media to foster autonomy}

Statement 21. Social media is a powerful tool for learning a language.

Statement 22. Social media and YouTube videos increase motivation for learning a language

Statement 23. Social media helps me in becoming an autonomous learner.

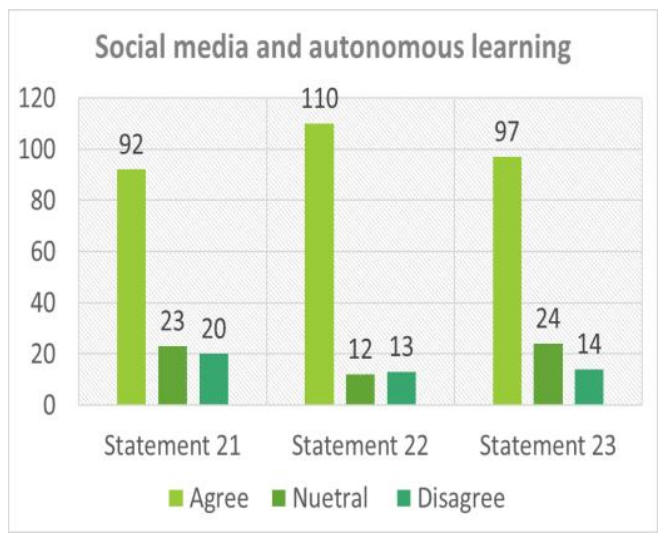

Fig. 5. Learner's perception on the role of social media

Analysis: The research observes the role of social media on EFL learners in achieving independence in their learning. More than $80 \%$ of EFL learners believe that social media is a powerful tool for learning a language like the use of Facebook, Twitter and YouTube videos has increased their motivation for learning a language. Social media has helped them in becoming autonomous learners. Only a small proportion of students felt that there is no benefit of using social media for EFL learning and achieving autonomy.

\subsection{Interview Questions}

Question 1. Is learning without a teacher possible? Have you ever tried to solve any task yourself at home?

Analysis of Responses: A vast majority of the students have agreed that they try to solve tasks by themselves at home and some students were able to complete their tasks successfully. However, a vast majority of students believe that it is very hard for them to do different tasks independently without the assistance of their teachers. One respondent said, "Yes I did, however, it is impossible to learn without the teacher because the teacher helps me in doing the tasks." Some students suggested that students who were studying online or distance learning should be trained to do their tasks independently. However, they also acknowledged that the role of the teacher cannot be denied or the role of the teacher cannot be completely ruled out of the class.

Question 2. Do you think teachers make efforts to help you learn the language independently? How?

Analysis of Responses: The learners responded positively to this question. A large number of students agree that teachers were consciously making efforts to foster autonomy in them by assigning them different tasks both inside and outside the classroom. The learners have mentioned that they feel that the teachers try to help them by assigning home tasks and asking direct questions to the students. Some students testify that they feel confident when the teacher provides them with extra practice material and guidance, these resources help them to understand the tasks as well as to do different tasks independently. Some students realize that problem-based tasks and classroom presentations have also helped them boost their confidence to do their work independently and find the solution to the problems given to them as tasks. Some students also find that the use of social media and YouTube videos have also helped to improve their learning by themselves which were recommended by the teacher. A large number of students also find that research projects and assignment assigned by the teacher helped them to improve their critical thinking, boosted their confidence, improved their understanding on working in teams which ultimately led them to develop autonomy and responsibility in them. 


\section{Question 3. What strategies do you think were helpful for you to develop autonomy on your own?}

Analysis of Responses: The learners have shared very interesting facts and their experiences while talking about developing autonomy and self-dependence in learning. Most of the learners have realized that studying extra resource material from reference books or published online has helped them boost their confidence and have also increased their knowledge. Some learners reported that peer teaching has also been very effective in building confidence and teamwork among them. Similarly, students have also reported that home assignments, inside and outside classroom tasks, projects, problem-based learning, presentation skills have also been helpful to make them responsible and motivated towards their learning. Some students have also found that using social media websites and watching YouTube videos have also been very effective to improve not only their language proficiency, social contacts, personal and course-related knowledge but also helped them work independently with great motivation and interest in studies.

\section{Question 4. What problems do you face in doing different tasks and studies on your own?}

Analysis of Responses: The most serious issue which a vast majority of the students have complained about is the course material and curriculum. They mentioned that some coursebooks were written in Western contexts and the language and terminologies used in that books were so complicated that the learners were unable to understand the concept clearly and completely. Additionally, they also mentioned that the tasks given at the end of every unit were very complex which they were unable to do completely without the assistance of the teacher. So, the learners have suggested using such a curriculum and study material that is comprehensive, relevant to their culture and context, and exercises were designed to help them build their autonomy. Secondly, some learners were least motivated and do not like the subject. So, they find that they were studying the course because it is compulsory to study at university. Therefore, they have shown very little interest in learning and improving their language ability. Some students inform that they have never gone to the library to study extra study material or reference material because they do not know how to use them for their studies. In addition to that, some learners have also complained about their social and domestic responsibilities which left them with no time to study even their course material and ultimately resulted in the losing their confidence and interest in learning the language in the classroom. Students have also mentioned that since Arabic which is their mother tongue is frequently used domestically, professionally and in social activities which leave them no choice to practice, learn and improve their language ability and they lose confidence as they feel shy to speak in front of other people.

\subsection{Learner Self-Support Model to achieve Learner Autonomy}

The researcher as an ELT expert also thinks that the learners also need to make serious and consistent efforts by themselves by following different both in-class and class strategies. The researcher has proposed a 'Learner Self-Support Model" which may provide a pathway for the learners to achieve autonomy through their self-support and without any external intervention. There are four stages in this proposed model to achieve autonomy in learning. According to this model, first of all, a learner has to plan different activities in which he is highly interested in participating and he has to be highly motivated and engaged in the planning stage. The researcher has proposed some activities that can be quite engaging for learners, such as group work or pair work, reciprocal teaching to classmates in the class, engagement in classroom discussion and competitions, and use of social media websites and online blogs to improve his learning, etc. The learner to select wisely which resource is the most effective in developing his interest in learning and his desire to achieve learner autonomy. The next step is 'Practice', a learner has to put vigorous efforts and continuous practice of different activities independently both inside and outside the classroom context to achieve autonomy. The third stage is the "Evaluation" or "Reflection" stage. After each activity, the learner is advised that he should evaluate or reflect on his performance and analyse how much he is successful in completing the task successfully and the shortcomings or hurdles in performing the task successfully. The fourth stage is the "Attainment" or "achievement" stage where a learner through his continuous efforts is successful in achieving autonomy in learning and can perform any task or able to take complete responsibility for his learning.

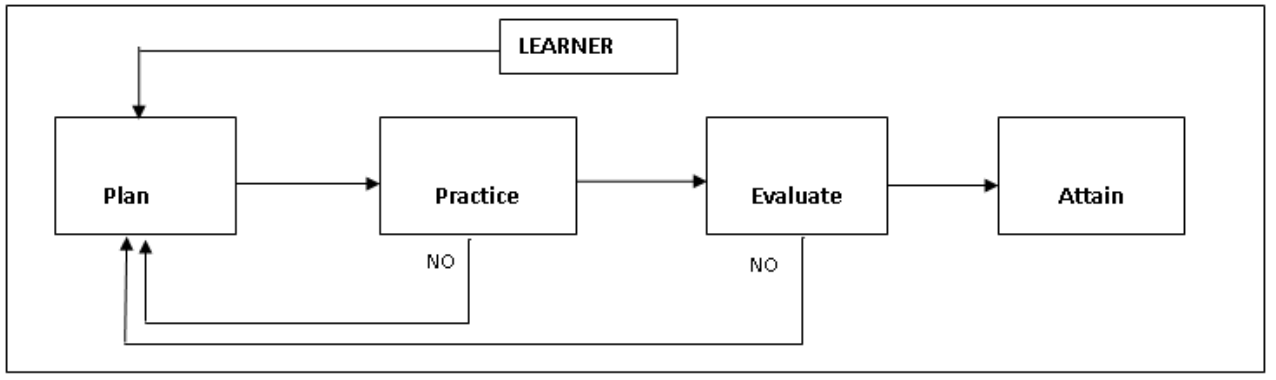

Fig. 6 Learner Self-Support Model to achieve Learner Autonomy 
The researcher believes that the learner should be highly committed and consistent to achieve autonomy through this model. Certain factors are connected with learners directly. For example, proficiency of learners in a language, motivation, sense of responsibility, social and cultural attributes, learning styles, self-confidence, and attitude to learning also affect the learners' desire to achieve autonomy an EFL classroom.

\section{Discussion and Conclusion}

The study has revealed that tertiary learners studying at Dhofar University have confirmed that they understand and realize the importance of learner autonomy. They believe that autonomy at university will equip them with self-esteem, confidence and authority to take control of their learning which is an important aspect of learning at university (Lee, Mann, \& Frank, 2010; Scharle \& Szabó,2000; Benson, 2013). The learners also acknowledge that a language instructor in the class can complete different tasks successfully. Teacher scaffolding to foster autonomy is appreciated and valued by the learners and in the Arab EFL context, it is essential to support learners to achieve this milestone (Borg \& Busaidi, 2012; Al-Asmari, 2013; Al-Issa, 2014).

The EFL learners insist on selecting course material relevant to the local culture and the learners' learning context. It will not help learners understand the different concept easily but will also enable the learners to build on their knowledge themselves without a teacher's intervention. (Blidi, 2017)

The researcher has also found that if the learners are involved in studying different resource and reference materials published in the form of books, journals and periodicals and available online which is beside the allocated course material is also helpful for the learners to improve their interest in learning and to develop autonomy in learning. The EFL learners also appreciated the role of peers in developing self-confidence, teamwork, learning strategy, self-reflection on the learning process and motivation in them. (Shen et al., 2020; Judy Shih; 2020)

The $21^{\text {st }}$ century is the age of digital learning and social media has completely changed the landscape of teaching and learning and the majority of the learner almost $97 \%$ of the learners use social media somehow in one way or another in daily (Kolhar et al. 2021). The EFL learners at Dhofar University also realized and acknowledged the role of social medial in EFL learning and autonomy development at the tertiary level. The majority of the participants believe that social media resources like YouTube videos, Facebook, Twitter and other social media websites are effective resource in building self-confidence, effective language learning, motivation and engagement in the learning process. (Eisenlauer, 2020; Kolhar et al. 2021).

The researcher has found that learners at Dhofar University have a clear understanding of the importance and need to develop learner autonomy and believe that peers, teachers, curriculum design, and learning technologies like social media can help them achieve learner autonomy. Moreover, the researcher has proposed a self-support model for learners to achieve autonomy which he believes can help learners to foster autonomy if carefully practised by the learners.

\section{Recommendations}

The recent study has been done on the EFL learners studying at the tertiary level in the context of Oman specifically in the context of Dhofar University, Oman. The future research can focus on the number of other factors like the teachers' scaffolding in developing learner autonomy in EFL learners in the Arab region, peers role in developing autonomy in an Arab EFL context and the role of social media in developing autonomy in learners under the circumstances of online or distance learning. The study can also be expanded to the other Higher Education Institutions in the Dhofar region and the other regions of Oman.

Funding: This research received no external funding.

Acknowledgements: I would also like to extend my gratitude to the participants in the Foundation Year Program and the Department of English Langauge \& Literature at Dhofar University, Salalah, Oman, who voluntarily affirmed their availability and contributed to this research by sharing their reflections. I want to thank Dhofar University Research Board (URB) members who encouraged me through their approval to conduct this research and I am thankful to everyone who contributed and supported this research in every possible way.

Conflicts of Interest: There is no conflict of interest.

\section{References}

[1] Al Asmari, A. (2013). Practices and Prospects of Learner Autonomy: Teachers' Perceptions. English Language Teaching, 6(3), 1-10.

[2] Al-Issa, A. S. (2014). A critical examination of motivation in the Omani English language education system. Journal of Language Teaching and Research, 5(2), 406.

[3] Baby, K. T., \& Saeed, M. A. (2020). Beyond the Classroom Through the Paperless Mode. International Journal of Linguistics, Literature and Translation (IJLLT). https://ssrn.com/abstract $=3528345$

[4] Basri, F. (2020). Factors influencing learner autonomy and autonomy support in a faculty of education. Teaching in Higher Education, 1-16.

[5] Benson, P. (1997). The philosophy and politics of learner autonomy. In Autonomy and independence in language learning (pp. 18-34). Longman. 
[6] Benson, P., Chik, A., \& Lim, H. Y. (2003). Becoming autonomous in an Asian context: Autonomy as a sociocultural process. In Learner autonomy across cultures (pp. 23-40). Palgrave Macmillan, London.

[7] Benson, P. (2011). Teaching and researching: Autonomy in language learning. Routledge.

[8] Benson, P. (2013). Learner autonomy. TESOL Quarterly, 47(4), 839-843.

[9] Benson, P. (2017). Language Learning Beyond the Classroom: Access all Areas. Studies in Self-Access Learning Journal, 8(2).

[10] Blidi, S. (2017). Learner Autonomy and the MENA Region Context. In Collaborative Learner Autonomy (pp. 21-63). Springer, Singapore.

[11] Borg, S., \& Al-Busaidi, S. (2012). Learner autonomy: English language teachers' beliefs and practices. ELT journal, 12(7), 1-45.

[12] Camilleri, C., \& Malewska-Peyre, H. (1997). Socialization and identity strategies. Handbook of cross-cultural psychology, 2, 41-67.

[13] Deci, E. L., \& Ryan, R. M. (2016). Optimizing students' motivation in the era of testing and pressure: A self-determination theory perspective. In Building autonomous learners (pp. 9-29). Springer, Singapore.

[14] Eisenlauer, V. (2020). The EFL-YouTube remix: Empowering multimodal and computational literacies for EFL purposes. Journal of Visual Literacy, 1-18.

[15] Field, R., Duffy, J., \& Huggins, A. (2014). Independent learning skills, Self-determination theory and psychological well-being: Strategies for supporting the first year university experience. In Proceedings of the 17th International First Year in Higher Education Conference (pp. 1-10). Queensland University of Technology.

[16] Fredholm, A., Savin-Baden, M., Henningsohn, L., \& Silén, C. (2015). Autonomy as both challenge and development in clinical education. Learning, Culture and Social Interaction, 5, 20-27.

[17] Ghazali, F. A. (2020). Challenges and Opportunities of Fostering Learner Autonomy and Self-Access Learning During the COVID-19 Pandemic. Studies in Self-Access Learning Journal, 11(3).

[18] Griffiths, C., \& Soruç, A. (2020). Language learning strategies. In Individual Differences in Language Learning (pp. 113-129). Palgrave Macmillan, Cham.

[19] He, F., \& Teng, F. (2015). Assessing the correlation between VST, perception for the ability of reading comprehension and practical reading comprehension performance. ThaiTESOL Journal, 28(2), 14-36.

[20] Holec, H. (1981). Autonomy and Foreign Language Learning. Oxford Pergamon Press. (First Published 1979, Council of Europe).

[21] Judy Shih, H. C. (2020). The use of individual and collaborative learning logs and their impact on the development of learner autonomy in the EFL classroom in Taiwan. Innovation in Language Learning and Teaching, 1-15.

[22] Kolhar, M., Kazi, R. N. A., \& Alameen, A. (2021). Effect of social media use on learning, social interactions, and sleep duration among university students. Saudi Journal of Biological Sciences.

[23] Lee, Y. M., Mann, K. V., \& Frank, B. W. (2010). What drives students' self-directed learning in a hybrid PBL curriculum. Advances in Health Sciences Education, 15(3), 425-437.

[24] Levett-Jones, T. L. (2005). Self-directed learning: implications and limitations for undergraduate nursing education. Nurse Education Today, 25(5), 363-368.

[25] Little, D. (2000). Autonomy and autonomous learners. Routledge encyclopaedia of language teaching and learning, 69-72.

[26] Meyer, B., Haywood, N., Sachdev, D., \& Faraday, S. (2008). What is independent learning and what are the benefits for students. Department for Children, Schools and Families Research Report, 51.

[27] Oslund, L. E. (2015). Teaching style preferences of educators: A meta-analysis.

[28] Oxford Advanced Learner's Dictionary (n.d.). Autonomy. In oxfordlearnersdictionaries.com dictionary. Retrieved February 17, 2021, from https://www.oxfordlearnersdictionaries.com/definition/english/autonomy?q=autonomy

[29] Oxford, R. L. (2002). Language learning strategies in a nutshell: Update and ESL suggestions. Methodology in language teaching: An anthology of current practice, 4(3), 124-132.

[30] Oxford, R. L. (2003). Toward a more systematic model of L2 learner autonomy. In Learner autonomy across cultures (pp. 75-91). Palgrave Macmillan, London.

[31] Oxford, R. L. (2015). Expanded perspectives on autonomous learners. Innovation in Language Learning and Teaching, 9(1), 58-71.

[32] Oxford, R. L., \& Amerstorfer, C. M. (Eds.). (2018). Language learning strategies and individual learner characteristics: Situating strategy use in diverse contexts. Bloomsbury Publishing.

[33] Rinkoff, C. Z. (2007). Learning styles diversity: Implications for the organizational culture of university student cohorts. Capella University.

[34] Scharle, A., \& Szabo, A. (2007). Learner autonomy: A guide to developing learner responsibility. Ernst Klett Sprachen.

[35] Shen, B., Bai, B., \& Xue, W. (2020). The effects of peer assessment on learner autonomy: An empirical study in a Chinese college English writing class. Studies in Educational Evaluation, 64, 100821.

[36] White, C. B. (2007). Smoothing out transitions: How pedagogy influences medical students' achievement of self-regulated learning goals. Advances in Health Sciences Education, 12(3), 279-297.

[37] White, C. B., \& Fantone, J. C. (2010). Pass-fail grading: laying the foundation for self-regulated learning. Advances in health sciences education, 15(4), 469-477.

[38] Zimmerman, B. J. (2000). Attaining self-regulation: A social cognitive perspective. In Handbook of self-regulation (pp. 13-39). Academic Press. 